Revista Complutense de Educación

ISSNe: 1988-2793

http://dx.doi.org/10.5209/RCED.61869

\title{
La escuela de ayer, hoy y mañana. Claves y desafíos
}

Autor: Fernández Tilve, Mª D. y Fernández Suárez, G. F. (Coords.)

Editorial: Dykinson

Año de publicación: 2016

$N^{o}$ de Páginas: 251

ISBN: 978-84-9085-871-4

El libro La escuela de ayer, hoy y mañana. Claves y desafíos, coordinado por $\mathrm{M}^{\mathrm{a}}$ Dolores Fernández Tilve y Gonzalo Francisco Fernández Suárez, pretende arrojar un poco de luz sobre la dirección que debe tomar la escuela que necesita la ciudadanía de nuestro tiempo. En particular, en quince capítulos escritos por cerca de una veintena de expertos, precedidos del prólogo que firma la alcaldesa de Lugo, la obra plantea, de manera clara y precisa, algunos de los principales problemas que afectan a la escuela y a sus profesionales, poniendo sobre la mesa varios retos que es preciso asumir con cierta urgencia.

Partiendo de la escuela de ayer, en el capítulo que inaugura la obra, el profesor Fernández Suárez estudia la situación de las instituciones educativas en la ciudad de Lugo en el S. XI. Continúa Juan Carlos Pardo Pérez analizando cómo la introducción del enfoque de las competencias en la escuela postmoderna constituye un dispositivo ideológico y tecnocrático que promueve la selección y clasificación del alumnado. Los capítulos tercero y cuarto, firmados por Belisario S. San José y Manuel Losada, respectivamente, se centran en la regulación normativa de nuestro sistema educativo, atendiendo, primero, a los cambios que introduce la LOMCE y, luego, al desarrollo y concreción del texto normativo en Educación Primaria y Educación Secundaria en Galicia.

En el quinto capítulo José Manuel Suárez Santodomingo destaca la relevancia de la familia como contexto primogénito de la educación en valores, para luego abordar la situación de mayor vulnerabilidad que afecta a los menores en situación de desamparo. Y en el sexto, Pilar Quicios García se centra en la atención a la diversidad en nuestro país insistiendo en la necesidad de que el profesorado disponga de la formación didáctica y pedagógica que requiere dar respuesta a las necesidades del alumnado. A las puertas del ecuador del libro, la profesora Alcínia Noutel se detiene en la situación de los jóvenes que sufren tóxicodependencia destacando la importancia de intervenir de manera temprana en su prevención, cuestión en la que familias y escuela tienen un papel clave. Retomando el desafío de la atención a la diversidad, Iker Sertucha Lista se centra en la situación educativa que afecta al alumnado con sordera. Aún reconociendo el incremento de los recursos humanos y materiales destinados a su atención educativa, el autor deja claro que el incremento en los niveles de escolarización no se ha traducido en mayores índices de integración. 
Tras situar los desafíos que introduce el enfoque por competencias en la tarea orientadora, Laura Malvar y $\mathrm{M}^{\mathrm{a}}$ Dolores Fernández Tilve tratan de dibujar el perfil profesional del orientador a partir de los documentos que regulan la función orientadora en Galicia. Además de concretar el perfil competencial que plantea la Administración educativa, las autoras concluyen que es necesario otorgarle una mayor presencia a las competencias "saber ser y saber estar".

Con un título muy sugerente, Quintín Álvarez Núñez atiende a la necesidad de introducir la educación emocional en la escuela haciendo hincapié en la importancia de que este propósito impregne el funcionamiento del centro educativo a todos los niveles.

El capítulo once, escrito por Antonio Rial Boubeta y Patricia Gómez Salgado, aborda uno de los grandes retos de la escuela para este siglo XXI. Sin dejar de reconocer sus riesgos, los autores insisten en que la red constituye una excelente oportunidad educativa y de desarrollo personal si se dispone de la educación como estrategia preventiva.

La parte final de libro, integrada por los capítulos que van del doce al quince, se centran específicamente en el profesorado. El número doce, firmado por Eduardo Fuentes Abeledo y Nuria Abal Alonso, ahonda en la formación inicial de maestros como un elemento determinante en su futuro ejercicio profesional. Por su parte $\mathrm{M}^{\mathrm{a}}$ Dolores Fernández Tilve y Marta Poncet Souto en el capítulo trece, exploran el proceso de construcción de la identidad profesional del estudiantado que inicia el Grado de Maestro en Educación Primaria y lo relacionan con sus motivaciones para decantarse por la profesión docente. El penúltimo capítulo, cuyo autor es José María Aguilera Carrasco, atiende a los desafíos que deben asumir las instituciones educativas y sus profesionales con la introducción de las TIC en el aula. Cierran la obra Ana $\mathrm{M}^{\mathrm{a}}$ Baena Ampudia y $\mathrm{M}^{\mathrm{a}}$ Dolores Fernández Tilve profundizando en el papel que ejercen los sindicatos como agentes promotores de la formación permanente del profesorado.

Sin lugar a dudas, en un contexto como el actual, en el que la escuela debe hacer frente a un buen número de desafíos, necesitamos valorar y reflexionar críticamente sobre el rumbo que debe tomar una institución a la que la sociedad ha encomendado la formación de la ciudadanía. Justamente con un panorama de fondo como este, cobra fuerza la pertinencia de un libro que aborda sin rodeos algunos de los principales problemas de la escuela.

Diana Priegue Caamaño Universidad de Santiago de Compostela diana.priegue@usc.es 